\title{
WT1 247-261 Peptide Vaccine
}

National Cancer Institute

\section{Source}

National Cancer Institute. WT1 247-261 Peptide Vaccine. NCI Thesaurus. Code C104737.

A synthetic peptide vaccine consisting of a HLA-DRw53-restricted human Wilms' Tumor protein-1 (WT 1) peptide comprised of amino acids 247 through 261, a HLA class IIrestricted WT1 peptide, with potential immunomodulating and antitumor activities. Vaccination with WT1 247-261 peptide may stimulate a CD4-positive helper Tlymphocyte-mediated immune response against WT 1 expressing cells. Activated helper T-cells stimulate dendritic cells, and activate the proliferation of other T-lymphoctes and B-lymphocytes. This causes tumor cell lysis and inhibition of cancer cell proliferation in WT 1-overexpressing tumor cells. WT 1, a zinc finger DNA-binding protein, is overexpressed in most types of leukemia and in a variety of solid cancers. 